\title{
Characteristics of body composition and cardiometabolic risk of Japanese male heavyweight Judo athletes
}

\author{
Hiroko Murata ${ }^{2}$, Satomi Oshima', Suguru Torii ${ }^{1}$, Motoko Taguchi $^{1}$ and Mitsuru Higuchi ${ }^{1 *}$
}

\begin{abstract}
Background: The purpose of this study was to clarify the characteristics of body composition and cardiometabolic risk of Japanese male heavyweight Judo athletes compared with heavyweight athletes of other sports.

Methods: Nineteen heavyweight Judo athletes (mean age, $20.4 \pm 1.1$ years), as well as 22 heavyweight (mean age, $21.5 \pm 0.9$ years) and 17 nonheavyweight (mean age, $21.1 \pm 0.8$ years) American football and Rugby football athletes in Japan participated in this study. Body composition was assessed by using dual-energy X-ray absorptiometry and magnetic resonance imaging. Cardiometabolic risk was evaluated by measuring blood biochemical variables.

Results: Heavyweight Judo athletes had significantly heavier body mass (122.7 $\pm 13.1 \mathrm{~kg}$ vs. $99.0 \pm 8.1 \mathrm{~kg}$ ), higher body fat percentage $(27.5 \% \pm 5.2 \%$ vs. $19.4 \% \pm 4.7 \%)$, and larger visceral fat cross-sectional area $\left(118 \pm 35 \mathrm{~cm}^{2}\right.$ vs. $\left.67 \pm 24 \mathrm{~cm}^{2}\right)(P<0.01)$ compared with heavyweight football players. Although the cardiometabolic risk was higher in heavyweight athletes compared to nonheavyweight athletes, there were no significant differences between heavyweight Judo and heavyweight Football athletes in the blood biochemical variables, except for high concentration of uric acid in heavyweight Judo athletes.

Conclusions: Even though heavyweight Judo athletes had more excess fat mass, especially VF mass, their cardiometabolic risk in terms of blood biochemical parameters was not significantly higher compared with heavyweight athletes of other sports. Therefore, excessive fat accumulation may not necessarily increase cardiometabolic risk for heavyweight Judo athletes.
\end{abstract}

Trial registration: This trial is registered with the University Hospital Medical Information Network Clinical Trial Registration (UMIN-CTR) UMIN000020564.

Keywords: Visceral fat, Obesity, Metabolically healthy obese, Uric acid

\section{Background}

Obesity, especially having visceral fat accumulation, is known to be a major risk factor in cardiovascular disease $[1,2]$. Heavyweight athletes, including those who participate in Judo, American football, and Rugby football, often intentionally try to increase their body mass (BM) because it significantly influences their athletic performance [3]. However, it was recently reported that heavyweight athletes have high cardiometabolic risk compared with nonheavyweight athletes, even though they are actively participating

\footnotetext{
*Correspondence: mhiguchi@waseda.jp

${ }^{1}$ Faculty of Sport Sciences, Waseda University, 2-579-15 Mikajima, Tokorozawa-shi, Saitama 359-1192, Japan

Full list of author information is available at the end of the article
}

in a sport [4-6]. Linemen in the National Football League in the USA have higher body fat percentage compared with players in other positions, and such excess body fat may increase the risk of metabolic syndrome, when they are actively playing [4]. This association is seen not only in Western athletes but also among Asian athletes [7]. Professional Chinese heavyweight athletes in strength sports including Judo and Wrestling are at significantly higher risk of cardiovascular disease compared with other sports or athletes in lower body weight classes of a same sport [7].

The heaviest weight class in Judo, over $100 \mathrm{~kg}$ class for male and over $78 \mathrm{~kg}$ for female does not have an upper limit in their BM regulation when athletes enter competitions. Therefore, Judo athletes in the heaviest weight 
class put significant effort toward maintaining or gaining BM. In fact, a previous study showed that heavyweight Judo athletes carry one of the heaviest BM and highest body fat percentage compared with other heavyweight athletes in other sports such as wrestlers and weightlifters [7]. As a result, heavyweight Judo athletes may have higher cardiometabolic risk compared with other heavyweight athletes. However, the previous study did not investigate body composition in detail, such as measuring body fat percentage by using dual-energy X-ray absorptiometry (DXA) and visceral fat (VF) by using magnetic resonance imaging (MRI) in relationship with cardiometabolic risk. If heavyweight Judo athletes indeed have high cardiometabolic risk, such risk may harm their present health. Furthermore, it may increase their risk of cardiovascular disease after they retire from their playing sport [8]. Therefore, the purpose of this study was to clarify the characteristics of body composition and cardiometabolic risk of Japanese male heavyweight Judo athletes compared with heavyweight athletes of other sports. We hypothesized that because heavyweight Judo athletes had higher body fat percentage [7], they expected to have excessive VF mass and increase cardiometabolic risk compared with heavyweight athletes in other sports.

\section{Methods}

\section{Participants}

We recruited 19 collegiate heavyweight Judo athletes from the All Japan University Judo Championships team as the heavyweight Judo group (mean age, 20.4 \pm 1.1 years). In 19 heavyweight Judo athletes, 18 athletes were categorized in over $100 \mathrm{~kg}$ weight class and one athlete was categorized $100 \mathrm{~kg}$ weight class without intentional weight loss. For comparison, 22 heavyweight athletes $(\mathrm{BM},>90 \mathrm{~kg})$ were recruited from linemen on an American football team and from forwards position on a Rugby football team as the heavyweight football group (mean age, $21.5 \pm 0.9$ years). Additionally, 17 nonheavyweight athletes $(\mathrm{BM},<90 \mathrm{~kg})$ also were recruited from the previously mentioned American football and Rugby football teams as the nonheavyweight group (mean age, $21.1 \pm 0.8$ years). These teams belonged to the National Collegiate Athletic Association Division 1 in Japan. All participants in this study were adequately informed about the study by verbal and written descriptions, and each participant provided written informed consent before starting the study. This study was approved by the Ethical Committee of Human Research of Waseda University for use of human subjects in accordance with the Declaration of Helsinki.

\section{Design and procedure}

The present cross-sectional study was designed to compare heavyweight Judo athletes (heavyweight Judo group) and heavyweight football athletes (BM, >90 kg; heavyweight football group). Additionally, in order to emphasize the cardiometabolic risk of heavyweight athletes, "heavyweight group," which included both heavyweight Judo and heavyweight football athletes, was setup to compare heavyweight and nonheavyweight athletes. Lower weight class Judo athletes were excluded from this study, since they were often involved in an intentional weight loss which may influence their metabolic state. We examined body composition parameters in detail by using DXA and MRI, while cardiometabolic risk was assessed by measuring blood biochemical variables in fasting state. All the measurements of participants were collected in the same laboratory facility in the morning during in-season

\section{Measurement of body composition parameters}

$\mathrm{BM}$ was measured to the nearest $0.1 \mathrm{~kg}$ by using an electronic scale (UC-321; A\&D, Tokyo, Japan) under fasting condition in the morning. Body height was measured to the nearest $0.1 \mathrm{~cm}$ by using a stadiometer (YL-65; YAGAMI, Nagoya, Japan) with minimal clothing. Body mass index (BMI) was calculated from the measured BM $(\mathrm{kg})$ and height $(\mathrm{m})$. Body fat percentage was assessed by using DXA (Hologic QDT-4500; Hologic, Waltham, MA, USA). Total fat mass and fat-free mass (FFM) were calculated from BM and body fat percentage. Waist circumference was measured to the nearest $0.1 \mathrm{~cm}$ by using an inelastic measuring tape at the midpoint between the inferior coastal margin and the superior border of the iliac crest. VF and subcutaneous fat (SF) cross-sectional areas were measured by using MRI (Signa 1.5T; General Electric Co., Milwaukee, WI, USA). Imaging conditions included a T1-weighted spin-echo and axial-plane sequence with a slice thickness of $10 \mathrm{~mm}$, repetition time of $140 \mathrm{~ms}$, and echo time of 12.3 ms. Cross-sectional images were scanned at the L45 level, which was commonly used in previous studies, especially in obese populations [9]. During scanning, subjects were required to hold their breath for approximately $30 \mathrm{~s}$ after inhalation to reduce respiratory motion artifacts. The images were transferred to a personal computer in DICOM file format. VF and SF crosssectional areas were determined using digital image analysis software (Slice-O-Matic 4.3 for Windows; Tomovision, Montreal, Canada). To minimize interobserver variation, all analyses were performed by the same investigator. The coefficient of variation was $2.4 \%$ for $\mathrm{VF}$ cross-sectional area and $0.1 \%$ for SF, respectively.

\section{Collection and analysis of blood samples}

Venous blood samples were collected between 7:00 AM and 10:00 AM after at least $12 \mathrm{~h}$ of overnight fasting. Aspartate aminotransferase (AST), alanine aminotransferase 
(ALT), and $\gamma$-glutamyl transpeptidase $(\gamma$-GTP) were used as indices of liver function. Total cholesterol, high-density lipoprotein cholesterol (HDL-C), and triglycerides (TGs) were analyzed as indices of the lipid profile. Low-density lipoprotein cholesterol (LDL-C) was calculated using the Friedewald equation [10]. Uric acid concentration (UA) was used as the index of uric acid metabolism. Furthermore, plasma glucose, serum insulin, and homeostasis model assessment insulin resistance (HOMA-IR) were assessed as indices of glucose metabolism. HOMA-IR was calculated from plasma glucose and serum insulin concentrations. All blood parameters were analyzed by Mitsubishi Chemical Medience, Inc. (Tokyo, Japan).

\section{Statistical analyses}

All statistical analyses were performed using SPSS version 22.0 (SPSS, Chicago, IL, USA). We examined differences in body composition variables and blood biochemical variables between heavyweight athletes group and nonheavyweight athletes group as well as the heavyweight Judo athletes group and heavyweight football athletes group using the unpaired $t$ test. Non-normally distributed variables were log transformed for analysis. Prevalence of each cardiometabolic risk factor was compared between heavyweight Judo, heavyweight football, and nonheavyweight groups using the chi-square test. All measurements were presented as mean $\pm \mathrm{SD}$ or median (from 25 to $75 \%$ quartile range). The statistical significance level was set at $P<0.05$.

\section{Results}

\section{Body composition}

The comparison of body composition variables between heavyweight group and nonheavyweight group was presented in Table 1. All body composition parameters were significantly higher in the heavyweight group, except for body height. Table 2 showed the comparison of body composition parameters between heavyweight Judo and heavyweight football groups. The heavyweight Judo group showed significantly higher values in the parameters of fatness compared with the heavyweight football group such as total fat percentage and VF.

\section{Cardiometabolic risk}

The comparison of blood biochemical variables between heavyweight group and nonheavyweight group were presented in Table 3. ALT, $\gamma$-GPT, UA, glucose, insulin, and HOMA-IR in heavyweight group were significantly higher than in nonheavyweight group. Table 4 showed the comparison of blood biochemical variables between heavyweight Judo group and heavyweight football. Only UA concentration was significantly higher in the heavyweight Judo group compared with in the
Table 1 Comparison of body composition variables between heavyweight and nonheavyweight groups

\begin{tabular}{lccc}
\hline & $\begin{array}{l}\text { Heavyweight } \\
(n=41)\end{array}$ & $\begin{array}{l}\text { Nonheavyweight } \\
(n=17)\end{array}$ & $\begin{array}{l}P \\
\text { value }^{\dagger}\end{array}$ \\
\hline Height $(\mathrm{cm})$ & $177.4 \pm 5.7$ & $175.6 \pm 3.9$ & 0.218 \\
Body mass $(\mathrm{kg})^{\dagger}$ & $110.0 \pm 16.0$ & $78.9 \pm 5.0$ & $<0.001$ \\
BMI (kg/m²) & $35.0 \pm 4.9$ & $25.6 \pm 1.9$ & $<0.001$ \\
Total fat percentage (\%) & $23.2 \pm 6.0$ & $13.0 \pm 2.6$ & $<0.001$ \\
\multicolumn{1}{c}{ fat mass $(\mathrm{kg})^{\dagger}$} & $26.2 \pm 10.1$ & $10.3 \pm 2.6$ & $<0.001$ \\
$\quad$ fat free mass (kg) & $83.8 \pm 8.1$ & $68.5 \pm 3.4$ & $<0.001$ \\
Waist circumference (cm) & $103 \pm 10$ & $82 \pm 4$ & $<0.001$ \\
VF $\left(\mathrm{cm}^{2}\right)^{\dagger}$ & $91 \pm 39$ & $33 \pm 14$ & $<0.001$ \\
SF $\left(\mathrm{cm}^{2}\right)$ & $321 \pm 135$ & $94 \pm 46$ & $<0.001$ \\
\hline
\end{tabular}

Data were expressed as mean \pm SD. $B M I$ body mass index, $V F$ visceral fat area, $S F$ subcutaneous fat area; ${ }^{*}$ Log-transformed variables for non-normally distributed variables (body mass, total fat mass, VF) were used. ${ }^{\dagger} P$ value for difference between heavyweight Judo and football groups was assessed by unpaired $t$ test. Significant differences, $P<0.05$

heavyweight football group. Figure 1 showed the prevalence of cardiometabolic risk assessed by blood biochemical analysis in all three groups. The prevalence of abnormally high ALT in both the heavyweight Judo and heavyweight football groups was significantly higher than that in the nonheavyweight group. Additionally, the prevalence of abnormally high UA and TG levels in the heavyweight Judo group was significantly higher than those in the nonheavyweight group. The prevalence of other components, such as AST, $\gamma$-GTP, HDLC, LDL-C, and HOMA-IR, were not significantly different between the three groups.

Table 2 Comparison of body composition variables between heavyweight Judo and football groups

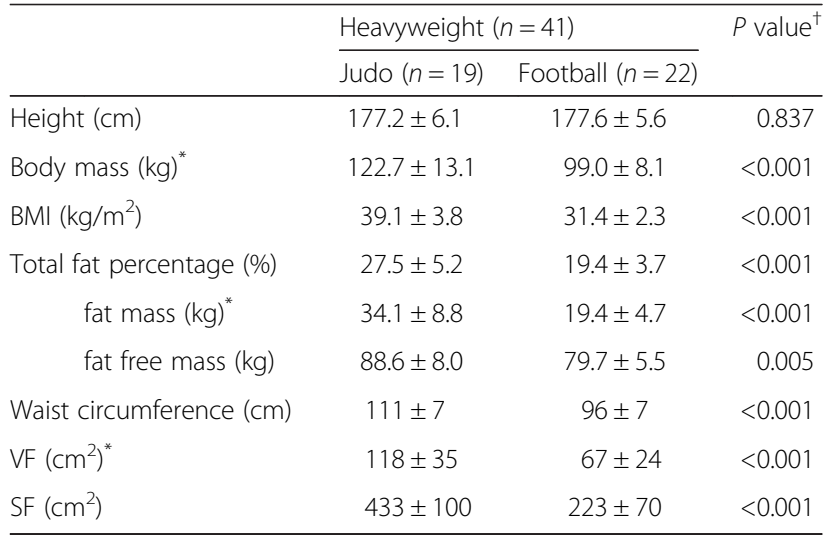

Data were expressed as mean \pm SD. $B M I$ body mass index, $V F$ visceral fat area, $S F$ subcutaneous fat area; *Log-transformed variables for non-normally distributed variables (body mass, total fat mass, VF) were used. ${ }^{\dagger} P$ value for difference between heavyweight Judo and football groups was assessed by unpaired $t$ test. Significant differences, $P<0.05$ 
Table 3 Comparison of blood biochemical parameters between heavyweight and nonheavyweight groups

\begin{tabular}{|c|c|c|c|c|}
\hline & $\begin{array}{l}\text { Heavyweight } \\
(n=41)\end{array}$ & $\begin{array}{l}\text { Nonheavyweight } \\
(n=17)\end{array}$ & $P$ value ${ }^{\ddagger}$ & $\begin{array}{l}\text { Normal } \\
\text { range }\end{array}$ \\
\hline $\mathrm{AST}^{*}(\mathrm{U} / \mathrm{L})$ & $28(24-38)$ & $24(20-30)$ & 0.053 & $10-40$ \\
\hline$A L T^{*}(U / L)$ & 38 (29-49) & $20(15-27)$ & $<0.001$ & $5-45$ \\
\hline$\gamma-G T P^{*}(U / L)$ & $32(26-44)$ & $23(15-26)$ & $<0.001$ & $<80$ \\
\hline Total-C (mg/dL) & $179 \pm 32$ & $179 \pm 31$ & 0.966 & $120-219$ \\
\hline $\mathrm{HDL}-\mathrm{C}(\mathrm{mg} / \mathrm{dL})$ & $48 \pm 8$ & $51 \pm 6$ & 0.220 & $40-85$ \\
\hline $\mathrm{LDL}-\mathrm{C}^{\dagger}(\mathrm{mg} / \mathrm{dL})$ & $105 \pm 30$ & $109 \pm 24$ & 0.581 & $\leqq 140$ \\
\hline $\mathrm{TG}^{*}(\mathrm{mg} / \mathrm{dL})$ & $112(75-165)$ & $80(66-110)$ & 0.086 & 30-149 \\
\hline $\mathrm{UA}(\mathrm{mg} / \mathrm{dL})$ & $6.9 \pm 1.5$ & $6.2 \pm 1.0$ & 0.048 & $3.8-7.0$ \\
\hline $\mathrm{FPG}^{*}(\mathrm{mg} / \mathrm{dL})$ & 85 (82-91) & $80(78-84)$ & 0.012 & 70-109 \\
\hline Insulin* ( $\mu \mid \mathrm{U} / \mathrm{mL})$ & $8.4(5.7-11.3)$ & $5.3(4.4-6.5)$ & 0.011 & $1.7-10.4$ \\
\hline HOMA-IR* & $1.72(1.13-2.52)$ & $1.02(0.91-1.36)$ & 0.008 & $<2.50$ \\
\hline
\end{tabular}

Data were expressed as mean $\pm \mathrm{SD}$ or median (inter quartile range). AST aspartate aminotransferase, $A L T$ alanine aminotransferase, $\gamma$-GTP $\gamma$-glutamyl transpeptidase, Total-C total cholesterol, HDL-C high-density lipoprotein cholesterol, LDL-C lowdensity lipoprotein cholesterol, TG triglyceride, UA uric acid, FPG fasting plasma glucose, HOMA-IR homeostasis model assessment insulin resistance, *Log-transformed variables for non-normally distributed variables (AST, ALT, $\gamma$-GTP, TG, FPG, insulin, HOMA-IR) were used to analysis. ${ }^{\dagger}$ The low-density lipoprotein cholesterol (LDL-C) was calculated using the Friedewald equation. ${ }^{\ddagger} P$ value for difference between heavyweight and nonheavyweight groups was assessed by unpaired $t$ test. Significant differences, $P<0.05$

Table 4 Comparison of blood biochemical parameters between heavyweight Judo and football groups

\begin{tabular}{|c|c|c|c|c|}
\hline & \multicolumn{2}{|c|}{ Heavyweight $(n=41)$} & \multirow[t]{2}{*}{$P$ value $^{\ddagger}$} & \multirow{2}{*}{$\begin{array}{l}\text { Normal } \\
\text { range }\end{array}$} \\
\hline & Judo $(n=19)$ & Football $(n=22)$ & & \\
\hline $\mathrm{AST}^{*}(\mathrm{U} / \mathrm{L})$ & $28(20-44)$ & $30(24-37)$ & 0.856 & $10-40$ \\
\hline $\mathrm{ALT}^{*}(\mathrm{U} / \mathrm{L})$ & $36(23-54)$ & $40(31-48)$ & 0.872 & $5-45$ \\
\hline$\gamma-G T P^{*}(U / L)$ & $29(23-43)$ & $35(28-47)$ & 0.371 & $<80$ \\
\hline Total-C (mg/dL) & $174 \pm 33$ & $183 \pm 31$ & 0.373 & 120-219 \\
\hline $\mathrm{HDL}-\mathrm{C}(\mathrm{mg} / \mathrm{dL})$ & $47 \pm 8$ & $49 \pm 8$ & 0.470 & $40-85$ \\
\hline $\mathrm{LDL}-\mathrm{C}^{\dagger}(\mathrm{mg} / \mathrm{dL})$ & $96 \pm 35$ & $112 \pm 24$ & 0.107 & $\leqq 140$ \\
\hline $\mathrm{TG}^{*}(\mathrm{mg} / \mathrm{dL})$ & 135 (90-185) & $103(66-131)$ & 0.107 & 30-149 \\
\hline UA (mg/dL) & $7.4 \pm 1.3$ & $6.4 \pm 1.5$ & 0.026 & $3.8-7.0$ \\
\hline $\mathrm{FPG}^{*}(\mathrm{mg} / \mathrm{dL})$ & 83 (79-90) & 87 (83-91) & 0.333 & 70-109 \\
\hline Insulin* ( $\mu \mathrm{IU} / \mathrm{mL})$ & $8.6(4.9-11.7)$ & $7.7(5.8-11.4)$ & 0.707 & $1.7-10.4$ \\
\hline HOMA-IR* & $1.99(1.05-2.42)$ & $1.58(1.16-2.77)$ & 0.631 & $<2.50$ \\
\hline
\end{tabular}

Data were expressed as mean \pm SD or median (inter quartile range). AST aspartate aminotransferase, ALT alanine aminotransferase, $\gamma$-GTP $\gamma$ - glutamyl transpeptidase, Total-C total cholesterol, $H D L-C$ high-density lipoprotein cholesterol, $L D L-C$ lowdensity lipoprotein cholesterol, TG triglyceride, UA uric acid, FPG fasting plasma glucose, HOMA-IR homeostasis model assessment insulin resistance; *Log-transformed variables for non-normally distributed variables (AST, ALT, $\mathrm{Y}$-GTP, TG, FPG, insulin, HOMA-IR) were used to analysis. ${ }^{\dagger}$ The low-density lipoprotein cholesterol (LDL-C) was calculated using the Friedewald equation. ${ }^{\ddagger} P$ value for difference between heavyweight Judo and Football groups were assessed by unpaired $t$ test. Significant differences, $P<0.05$

\section{Discussion}

This study examined the characteristics of body composition and cardiometabolic risk in heavyweight Judo athletes compared with heavyweight athletes in other sports. Our main finding in this study was that although heavyweight Judo athletes had higher body fat percentage and more fat mass, especially VF, their cardiometabolic risk in terms of blood biochemical parameters was not significantly higher than that in heavyweight football athletes. Mean BM of the heavyweight Judo group was approximately $20 \mathrm{~kg}$ heavier, and mean body fat percentage was approximately $8 \%$ higher than those of the heavyweight football group. Additionally, VF area of the heavyweight Judo group was about two times larger than that of the heavyweight football group (Table 2). Previous studies of non-athletes showed that cardiovascular disease was associated with accumulation of excess VF $[11,12]$. Therefore, we expected that the heavyweight Judo group would have higher cardiometabolic risk compared with the heavyweight football group. However, most blood biochemical variables were not significantly different between both heavyweight groups, except for UA concentration (Table 4). It is difficult to explain why the large fat mass of the heavyweight Judo group did not increase their cardiometabolic risk such as lipid profile and insulin relative to the heavyweight football group from results of this study. However, simply having more fat mass may not necessarily increase cardiometabolic risk in athletes. Previous studies reported the existence of metabolically healthy obese individuals, who have low risk of cardiovascular disease and insulin resistance $[13,14]$. For example, a follow-up study of metabolically healthy obese Italian individuals showed no increase in cardiovascular disease risk over 15 years [15]. Although the mechanism of metabolically healthy obesity is not clearly understood, it has been reported that increased physical activity may offset the high risk of cardiovascular disease in these individuals [16]. Additionally, another previous study reported that a high level of cardiorespiratory fitness was associated with lower prevalence of metabolic risk, even among obese individuals [17]. The heavyweight Judo athletes in this study participated in daily training for approximately $3 \mathrm{~h}$ including not only strength exercises but also a lot of high-intensity intermittent exercises which require physiological endurance. In fact, high-intensity intermittent exercise is a specific modality of Judo training [18]. Such training programs may help to increase their physical activity level and cardiorespiratory fitness regardless of their heavy BM $[19,20]$. Previous study demonstrated that male heavyweight Judo athletes in elite team have comparable aerobic capacity to professional defensive linemen as heavyweight football athletes [21, 22]. Therefore, Judo athletes may be similarly 


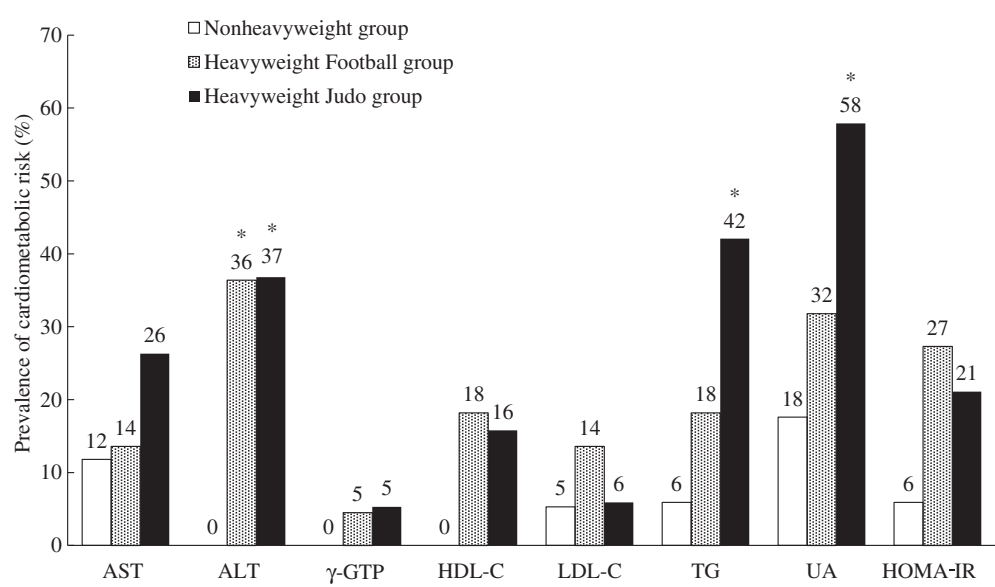

Fig. 1 Comparison of prevalence in cardiometabolic risk in terms of blood biochemical parameters. Prevalence of cardiometabolic risk presents the percentage over the referenced normal range of respective parameters. The cut-off referenced normal range were as follows: AST < 40 (U/L), ALT $<45(\mathrm{U} / \mathrm{L}), \gamma-G T P \geqq 80(\mathrm{U} / \mathrm{L}), \mathrm{HDL}-\mathrm{C}<40(\mathrm{mg} / \mathrm{dL}), \mathrm{LDL}-\mathrm{C} \leqq 140(\mathrm{mg} / \mathrm{dL}), \mathrm{TG} \geqq 150(\mathrm{mg} / \mathrm{dL}), \mathrm{UA}>7.0(\mathrm{mg} / \mathrm{dL}), \mathrm{HOMA}-\mathrm{IR} \geqq 2.5 .{ }^{*}$ Significant differences compared with Nonheavyweight group, $P<0.05$

metabolically active as heavyweight football players, and simply having more fat mass does not automatically increase cardiometabolic risk for athletes. At the same time, those heavyweight athletes still have higher risk of cardiometabolic risk compared to nonheavyweight athletes. Therefore, periodic biochemical tests to assess such risks are suggested to detect heavyweight athletes at high cardiometabolic risk. We should also note that only UA concentration was higher in the heavyweight Judo group compared with in the heavyweight football group (Table 4). The high concentration of UA is known to cause gout, and it has been reported that VF is the most influential factor in UA concentration [23]. Therefore, the larger VF mass of the heavyweight Judo athletes may have increased their UA concentration. At the same time, it has been reported that UA metabolism is influenced by both dietary intake and physical exercise [24]. High intake of meat and fish is known to be the dietary cause of increase in blood UA level. Heavyweight Judo athletes in this study may have a high intake of meat products to increase their energy and protein intake to gain BM as muscle mass. Moreover, high-intensity intermittent exercise increase hypoxanthine and UA metabolism [25]. Therefore, it is possible that diet and exercise may influence the UA level of heavyweight Judo athletes besides their large VF mass. However, diet and exercise were not assessed in this study. Therefore, further study to evaluate the influence of diet and/or exercise on cardiometabolic risk, including UA concentration, will help to elucidate the development of risk in heavyweight athletes.

The prevalence of abnormally high UA and TG levels was higher in the heavyweight Judo group compared with those in the nonheavyweight group (Fig. 1), even though mean UA and TG levels in the heavyweight Judo group were within or close to the reference normal range (Table 4). In other words, there are several heavyweight Judo athletes in this study who had abnormally high levels of UA and/or TG, but most of the heavyweight athletes were within its normal ranges by observing the individual results. Those athletes with higher UA and/or TG level did not necessarily carry more fat mass or VF mass. Additionally, there were no other anthropometric parameters commonly found in those who had abnormal blood biochemical parameters among Judo athletes. Therefore, athletes with increased cardiometabolic risk may be influenced by other factors such as genetic factors [26, 27], dietary habits [28, 29], or other lifestyle factors commonly related with cardiometabolic risks.

The present study has a few limitations. Firstly, this study design was a cross-sectional study, and thus, it is difficult to determine the cause and effect relationship in this study. Furthermore, larger sample sizes, prospective and interventional studies, are required to investigate the physiological mechanism of decreasing cardiometabolic risk in heavyweight Judo athletes despite their excessive fat mass.

\section{Conclusion}

Cardiometabolic risk in Japanese male heavyweight Judo athletes was not significantly higher compared with other heavyweight athletes, even though they had higher fat mass such as VF. Therefore, excessive fat accumulation may not necessarily increase cardiometabolic risk for heavyweight Judo athletes. 


\section{Abbreviations}

ALT: alanine aminotransferase; AST: aspartate aminotransferase; BM: body mass; BMI: body mass index; DXA: dual-energy X-ray absorptiometry; FFM: fat-free mass; HDL-C: high-density lipoprotein cholesterol; HOMAIR: homeostasis model assessment insulin resistance; LDL-C: low-density lipoprotein cholesterol; MRI: magnetic resonance imaging; SF: subcutaneous fat; TG: triglyceride; UA: uric acid; VF: visceral fat; $\gamma$-GTP: $\gamma$-glutamyl transpeptidase.

\section{Competing interests}

The authors declare that they have no competing interests.

\section{Authors' contributions}

$\mathrm{MH}, \mathrm{MT}$, and $\mathrm{HM}$ contributed to the conception and design. MT and HM collected the funds. SO, HM, and ST carried out the measurement. HM, SO, and $\mathrm{MH}$ analyzed and interpreted the data. HM and SO drafted the manuscript. $\mathrm{MH}$ revised the manuscript critically. All authors have given final approval.

\section{Acknowledgement}

This study was supported by the Waseda University Global Centre of Excellence Program, Sport Sciences for the Promotion of Active Life.

\section{Author details}

${ }^{1}$ Faculty of Sport Sciences, Waseda University, 2-579-15 Mikajima, Tokorozawa-shi, Saitama 359-1192, Japan. ${ }^{2}$ Graduate school of Sport Sciences, Waseda University, 112 Frontier Reseach Center 135-1 Horinouchi, Tokorozawa-shi, Saitama 359-1192, Japan.

Received: 28 January 2016 Accepted: 30 March 2016 Published online: 06 April 2016

\section{References}

1. Despres JP, Lemieux I. Abdominal obesity and metabolic syndrome. Nature. 2006;444(7121):881-87

2. Haslam DW James WPT. Obesity. Lancet. 2005:366(9492):1197-209.

3. Berglund L, Sundgot-Borgen J, Berglund B. Adipositas athletica: a group of neglected conditions associated with medical risks. Scand J Med Sci Sports. 2011;21(5):617-24

4. Borchers JR, Clem KL, Habash DL, Nagaraja HN, Stokley LM, Best TM. Metabolic syndrome and insulin resistance in division 1 collegiate football players. Med Sci Sports Exerc. 2009;41(12):2105-10.

5. Selden MA, Helzberg JH, Waeckerle JF, Browne JE, Brewer JH, Monaco ME, et al. Cardiometabolic abnormalities in current National Football League players. Am J Cardiol. 2009;103(7):969-71.

6. Bosch TA, Burruss TP, Weir NL, Fielding KA, Engel BE, Weston TD, et al. Abdominal body composition differences in NFL football players. J Strength Cond Res. 2014;28(12):3313-9.

7. Guo JJ, Zhang X, Wang L, Guo Y, Xie MH. Prevalence of metabolic syndrome and its components among Chinese professional athletes of strength sports with different body weight categories. PLoS One. 2013;8(11): e79758.

8. Miller MA, Croft LB, Belanger AR, Romero-Corral A, Somers VK, Roberts AJ, et al. Prevalence of metabolic syndrome in retired National Football League players. Am J Cardiol. 2008;101(9):1281-4.

9. Vissers D, Hens W, Taeymans J, Baeyens JP, Poortmans J, Van Gaal L. The effect of exercise on visceral adipose tissue in overweight adults: a systematic review and meta-analysis. PLoS One. 2013;8(2):e56415.

10. Friedewald WT, Levy RI, Fredrickson DS. Estimation of concentration of lowdensity lipoprotein cholesterol in plasma, without use of preparative ultracentrifuge. Clin Chem. 1972;18(6):499-502.

11. Fujioka S, Matsuzawa Y, Tokunaga K, Tarui S. Contribution of intraabdominal fat accumulation to the impairment of glucose and lipid metabolism in human obesity. Metabolism. 1987;36(1):54-9.

12. Matsuzawa Y, Fujioka S, Tokunaga K, Tarui S. Classification of obesity with respect to morbidity. Proc Soc Exp Biol Med. 1992;200(2):197-201.

13. Janiszewski PM, Ross R. Effects of weight loss among metabolically healthy obese men and women. Diabetes Care. 2010;33(9):1957-9.

14. Roberson LL, Aneni EC, Maziak W, Agatston A, Feldman T, Rouseff M, et al. Beyond BMI: the "Metabolically healthy obese" phenotype \& its association with clinical/subclinical cardiovascular disease and all-cause mortality-a systematic review. BMC Public Health. 2014;14:14.
15. Calori G, Lattuada G, Piemonti L, Garancini MP, Ragogna F, Villa M, et al. Prevalence, metabolic features, and prognosis of metabolically healthy obese Italian individuals: the Cremona study. Diabetes Care. 2011;34(1):210-15.

16. Gill JMR, Malkova D. Physical activity, fitness and cardiovascular disease risk in adults: interactions with insulin resistance and obesity. Clin Sci. 2006; 110(4):409-25.

17. Hong S, Lee J, Park J, Lee M, Kim JY, Kim KC, et al. Association between cardiorespiratory fitness and the prevalence of metabolic syndrome among Korean adults: a cross sectional study. BMC Public Health. 2014;14:481.

18. Franchini E, Brito CJ, Fukuda DH, Artioli GG. The physiology of judo-specific training modalities. J Strength Cond Res. 2014;28(5):1474-81. doi:10.519/JSC 0000000000000281

19. Franchini E, Del Vecchio FB, Matsushigue KA, Artioli GG. Physiological profiles of elite judo athletes. Sports Med. 2011;41(2):147-66.

20. Franchini $E$, Nunes AV, Moraes JM, Del Vecchio FB. Physical fitness and anthropometrical profile of the Brazilian male judo team. J Physiol Anthropol. 2007;26(2):59-67.

21. Borkowski L, Faff J, Starczewska-Czapowska J. Evaluation of the aerobic and anaerobic fitness in judoists from the Polish National Team. Biol Sport. 2001; 18(2):107-17.

22. Wilmore $\mathrm{JH}$, Haskell WL. Body composition and endurance capacity of professional football players. J Appl Physiol. 1972:33(5):564-67.

23. Hikita M, Ohno I, Mori Y, Ichida K, Yokose T, Hosoya T. Relationship between hyperuricemia and body fat distribution. Intern Med. 2007:46(17):1353-58.

24. Khanna D, Fitzgerald JD, Khanna PP, Bae S, Singh MK, Neogi T, et al. 2012 American College of Rheumatology guidelines for management of gout. Part 1: systematic nonpharmacologic and pharmacologic therapeutic approaches to hyperuricemia. Arthritis Care Res. 2012;64(10):1431-46.

25. Gerber T, Borg ML, Hayes A, Stathis CG. High-intensity intermittent cycling increases purine loss compared with workload-matched continuous moderate intensity cycling. Eur J Appl Physiol. 2014;114(7):1513-20.

26. Kim JA, Wei $Y Z$, Sowers JR. Role of mitochondrial dysfunction in insulin resistance. Circ Res. 2008;102(4):401-14.

27. Scuteri A, Sanna S, Chen WM, Uda M, Albai G, Strait J, et al. Genome-wide association scan shows genetic variants in the FTO gene are associated with obesity-related traits. Plos Genet. 2007;3(7):1200-10.

28. Kratz M, Baars T, Guyenet S. The relationship between high-fat dairy consumption and obesity, cardiovascular, and metabolic disease. Eur J Nutr. 2013;52(1):1-24

29. Mente A, de Koning L, Shannon HS, Anand SS. A systematic review of the evidence supporting a causal link between dietary factors and coronary heart disease. Arch Intern Med. 2009:169(7):659-69.

\section{Submit your next manuscript to BioMed Central and we will help you at every step:}

- We accept pre-submission inquiries

- Our selector tool helps you to find the most relevant journal

- We provide round the clock customer support

- Convenient online submission

- Thorough peer review

- Inclusion in PubMed and all major indexing services

- Maximum visibility for your research

Submit your manuscript at www.biomedcentral.com/submit 